\title{
A água como tema gerador do conhecimento químico: construindo um ensino-aprendizado contextual e cidadão no ensino de Química
}

\author{
Water as a stepping stone for the knowledge of Chemistry: building contextualized \\ and citizenship-oriented pedagogical practices
}

COELHO, Lucas Ribeiro. Graduando em Licenciatura em Química

Instituto Federal do Sertão Pernambucano - Campus Petrolina. Rua Maria Luiza de Araújo Gomes Cabral, S/N, João de Deus - Petrolina - Pernambuco - Brasil. CEP: 56.316-686 / Telefone: (87) 2101.4300 / E-mail: lucasribeirocoelho18@gmail.com

DOS ANJOS, Victor Hugo Almeida. Especialização em Ensino de Química e Biologia. Escola de Referência em Ensino Médio Antonio Padilha. Avenida Francisco Coelho Amorim, José e Maria Petrolina - PE - CEP: 56314-700 / Telefone: (87) 3864-9043 / E-mail: victor_hugoalm@hotmail.com

\section{DOS ANJOS, Débora Santos Carvalho. Doutora em Química}

Instituto Federal do Sertão Pernambucano - Campus Petrolina. Rua Maria Luiza de Araújo Gomes Cabral, S/N, João de Deus - Petrolina - Pernambuco - Brasil. CEP: 56.316-686 / Telefone: (87) 2101.4300 / E-mail: debora.santos@ifsertao-pe.edu.br

\section{RESUMO}

Este escrito apresenta e discute os resultados de uma pesquisa de intervenção desenvolvida por meio do Programa de Residência Pedagógica do IFSertãoPE com uma turma de 39 alunos, do $2^{\circ}$ ano D da Escola de Referência em Ensino Médio Antônio Padilha, durante os meses de novembro de 2020 a março de 2021. O estudo apoiou-se nos princípios da pesquisa qualitativa do tipo pesquisa-ação. Após levantamentos diagnósticos na escola, delimitou-se a seguinte questão-problema: como praticar o ensino de Química de modo contextualizado e cidadão? Desse modo, adotou-se o tema gerador água para contextualizar os conteúdos e a utilização de metodologias ativas, com o objetivo de investigar as contribuições das práticas educacionais desenvolvidas para a construção de um ensino-aprendizado contextual e cidadão no ensino de Química. As atividades planejadas seguiram o formato de ensino híbrido e foram organizadas desta forma: 1 ) aplicação de pré-teste; 2) execução de intervenções; 3 ) aplicação de pós-teste; e 4) análise e interpretação dos resultados. Evidenciouse que as atividades didático-pedagógicas realizadas contribuíram para oportunizar aprendizagens significativas no processo de ensino e de aprendizagem de Química e auxiliaram a formação de cidadãos críticos e reflexivos frente à temática dos recursos hídricos apresentada, bem como capazes de intervir de modo responsável no meio onde estão inseridos. Assim, as metodologias ativas e a contextualização dos conteúdos com o tema água apresentaram-se como possibilidades para a prática do ensino de Química contextual e cidadão.

Palavras-chave: Ensino de Química, Metodologias ativas, Contextualização, Água.

\section{ABSTRACT}

This paper presents and discusses the results of an intervention research carried out during the Teaching Residency Program of the Federal Institute in the Sertão region of the State of Pernambuco, Brazil (IFSertãoPE) in a class with 39 students of the second year of high school at the Antonio Padilha Reference School from November 2020 to March 2021. The study was based on the action research principles. After performing diagnostic surveys at the school, we came to the following problem-question: how to teach Chemistry in a way that is both contextualized and 
RIBEIRO, L. C., DOS ANJOS, V. H. A. e DOS ANJOS, D.S.C.

A água como tema gerador do conhecimento químico: construindo um ensino-aprendizado contextual e cidadão no ensino de Química

citizenship-oriented? Thus, we used water as a theme that could generate the contextualization of the subjects and used active learning methods to investigate the contributions of the teaching practices developed to the construction of contextualized and citizenship-oriented pedagogical practices in Chemistry. The activities were based on the hybrid teaching format and were organized as follows: 1) pre-test application; 2) execution of interventions; 3) post-test application; and 4) analysis and interpretation of results. We found that the didactic and pedagogical activities performed contributed to providing significant learning opportunities in Chemistry pedagogical practices and helped training citizens to be critical, reflective, and capable of intervening responsibly in their environment regarding water issues. Therefore, we found that active learning methods and the contextualization of Chemistry topics involving water are possibilities for the practice of a contextualized teaching of Chemistry that trains students to be citizens.

Keywords: Chemistry Teaching; Active learning methods; Contextualization; Water.

\section{Introdução}

A água, líquido mais comum na Terra e essencial à vida, tem despertado inquietudes em pesquisadores e em pessoas preocupadas com questões ambientais, devido à previsão de crise hídrica. Cerca de $97,4 \%$ de toda a água está presente nos oceanos, na forma de água salgada. $90 \%$ do total de água doce existente está concentrado nas geleiras e nas calotas polares, estando o restante em rios, em lagos, em lençóis freáticos e na atmosfera. A pequena quantidade de água apropriada para consumo humano está se esgotando gradativamente. O consumo irresponsável e sem fundamentação sustentável é um fator impulsionador de escassez hídrica, uma realidade já vivenciada no Brasil e em outros países (RIBEIRO; ROLIM, 2017).

Para que tal escassez seja evitada, ou amenizada, é preciso mobilizar a ação humana, principal responsável pelo atual cenário hídrico. Diante disso, evidencia-se a importância de trabalhar a temática na educação, pretendendo formar cidadãos conscientes e críticos, levando, para além dos muros da escola, o exercício da cidadania. Sob essa perspectiva, tratando-se do ensino de Química, Santos e Rodrigues (2018) pontuam que os recursos hídricos permitem abordar conteúdos químicos e ampliá-los com a exploração de aspectos socioambientais.

Nesse contexto, torna-se oportuna a aplicação de ações que contextualizam o ensino com os recursos hídricos. Dessa maneira, este escrito versa sobre os resultados de atividades de intervenção em ensino de Química desenvolvidas na Escola de Referência em Ensino Médio Antônio Padilha (EREM Antônio Padilha), escola-campo do Subprojeto Interdisciplinar/Química do Programa de Residência Pedagógica 2020, orientado pelo projeto institucional do Instituto Federal de Educação, Ciência e Tecnologia do Sertão Pernambucano (IFSertãoPE), sob gerenciamento da Coordenação de Aperfeiçoamento de Pessoal de Nível Superior (Capes).

Durante a diagnose da escola-campo, constatou-se alguma resistência dos alunos quanto à disciplina de Química. Tal fenômeno é frequentemente discutido na literatura e, possivelmente, resulta da complexidade dos conteúdos associada à forma como o ensino é praticado. Alves e Ribeiro (2020, p. 303) apontam que os conteúdos programáticos da disciplina de Química “[...] normalmente exigem um determinado nível de abstração, que os estudantes não estão habituados a 
RIBEIRO, L. C., DOS ANJOS, V. H. A. e DOS ANJOS, D.S.C.

A água como tema gerador do conhecimento químico: construindo um ensino-aprendizado contextual e cidadão no ensino de Química

lidar".

Diante disso, estruturou-se a seguinte questão-problema norteadora da pesquisa: como promover a prática do ensino de Química de modo contextualizado e cidadão? Nesse contexto, Coelho, Rodrigues e Sá-Silva (2020), após análise de trabalhos de intervenção enraizados na tentativa de modificar a rotina da sala de aula e superar problemas encontrados no ensino de Química, apontam que ações de perspectiva interventiva, quando bem-planejadas, podem favorecer a aprendizagem e fortalecer as relações entre os sujeitos envolvidos.

Partindo desse princípio e considerando os aspectos observados na EREM Antônio Padilha, o interesse em realizar esta pesquisa de intervenção com o tema gerador água surgiu da necessidade de desenvolver práticas educacionais inovadoras capazes de contribuir para a construção de um ensino-aprendizado qualitativo e contextualizado na disciplina de Química ofertada no Ensino Médio. Assim, supôs-se que o desenvolvimento de intervenções capazes de relacionar o tema gerador e os conteúdos programáticos é um caminho viável para solucionar duas problemáticas: a descontextualização dos conteúdos químicos e a aceleração das previsões de crise hídrica.

Para promover a abordagem contextualizada, adotou-se a utilização de métodos de ensino diversificados, denominados de metodologias ativas, visando a inserir o estudante no centro do processo educativo e melhorar qualitativamente os resultados de aprendizagem. Portanto, esse estudo objetivou investigar as contribuições de práticas educacionais fundamentadas no tema gerador água para a construção de um ensino de Química contextualizado e cidadão, adotando metodologias ativas em consonância com a matriz curricular do Ensino Médio.

\section{Fundamentação teórica}

$\mathrm{Na}$ literatura, comumente, discute-se que ensinar de forma ativa, contextualizada e com recursos pedagógicos adequados, garantindo uma aprendizagem significativa, é um dos desafios diagnosticados durante o processo educativo nos diversos níveis de ensino e componentes curriculares. Tratando-se da Química, sobretudo no Ensino Médio, Alves e Ribeiro (2020) destacam ser uma área que normalmente apresenta um grau de dificuldade expressivo.

Na concepção de Silva, Silva e Paula (2016), o ensino tradicional, muitas vezes centralizado na memorização dos conteúdos, tem grande parcela de contribuição para dificultar a aprendizagem. Diante da pluralidade discente e de suas particularidades de aprendizagem, no que diz respeito ao ritmo de estudo, bem como ao surgimento de novas metodologias e estratégias educativas, o ensino tradicional apresenta-se ineficaz ao processo de ensino e aprendizagem.

Nessa perspectiva, sugere-se que o docente planeje e execute ações de ensino de forma ativa e estabeleça a interação e a participação dos discentes por meio de atividades lúdicas e investigativas (ZAPATEIRO et al., 2017). Para isso, as metodologias ativas, métodos de ensino que tornam os estudantes os principais protagonistas do processo educativo, tendo o professor como mediador, mostram-se como alternativas de solução. 
RIBEIRO, L. C., DOS ANJOS, V. H. A. e DOS ANJOS, D.S.C.

A água como tema gerador do conhecimento químico: construindo um ensino-aprendizado contextual e cidadão no ensino de Química

$\mathrm{Na}$ visão de Simplício, Sousa e Anjos (2020), diversas atividades que assumem essa perspectiva, tais como mapa mental, quiz, experimentação, sala de aula invertida, processo orientado guiado em inquérito de aprendizagem (Pogil) e instrução por pares, são classificadas como metodologias ativas. Frente aos resultados dessas atividades, os autores destacam que o aluno:

[...] deixa de ser passivo e passa a ser autônomo, a ser ativo e a ser autor do próprio conhecimento. 0 professor, que antes era visto como o detentor de todo o conhecimento, agora se transforma em um mediador e em um facilitador do processo. 0 processo de ensino-aprendizagem, por sua vez, que na maioria das vezes é conteudista e estático, torna-se algo voltado ao desenvolvimento de conhecimentos, de habilidades e de atitudes, centrado na aprendizagem do aluno (SIMPLÍCIO; SOUSA; ANJOS, 2020, p. 433).

Seguindo essa linha de pensamento, importa salientar que não basta usufruir de diferentes metodologias, se o ensino continuar não atribuindo importância e significados práticos aos conteúdos curriculares. É preciso incorporar, dentro do trabalho docente, situações constituintes da realidade dos estudantes, gerando debates que contextualizem e atribuam aplicabilidade aos conteúdos e aos fenômenos explorados na disciplina. Nessa perspectiva, Santos e Rodrigues (2018) sugerem a adoção de temas geradores para trabalhar situações que norteiam os debates nas aulas de Química de maneira contextualizada e problematizadora.

O uso de temas geradores é defendido por vários autores e tem suas raízes na pedagogia freireana. Conforme Freire (1981, p. 110):

Estes temas se chamam geradores porque, qualquer que seja a natureza de sua compreensão como da ação por eles provocada, contém em si a possibilidade de desdobrar-se em outros tantos temas que, por sua vez, provocam novas tarefas que devem ser cumpridas.

Existe uma variedade de temáticas que podem ser inseridas no ambiente de ensino e aprendizagem. Santos e Rodrigues (2018, p. 65) destacam que a "[...] água, como tema gerador, tem sido tema de vários trabalhos na área de Educação Química". Os autores acrescentam que o uso desse eixo temático permite abordar uma série de conteúdos pertencentes a diversas áreas da Química, a exemplo de Química Geral, Química Orgânica, Química Inorgânica e Físico-Química, como também discutir questões socioambientais.

Por isso, o tema tem se mostrado relevante para a perspectiva de ensino contextualizado e cidadão, uma vez que o debate, em sala de aula, sobre aspectos sociais e ambientais é primordial para a significação da aprendizagem, à medida que favorece o desenvolvimento da capacidade dos alunos em tomarem decisões conscientes e se posicionarem diante de situações diferentes. Desse modo, formam-se cidadãos capazes de intervir de maneira responsável no meio onde se encontram (CHACON et al., 2016; FOLEIS et al., 2016).

\section{Material e métodos}


RIBEIRO, L. C., DOS ANJOS, V. H. A. e DOS ANJOS, D.S.C.

A água como tema gerador do conhecimento químico: construindo um ensino-aprendizado contextual e cidadão no ensino de Química

O estudo apoiou-se nos pressupostos da pesquisa de abordagem qualitativa, adotando intervenções pedagógicas nas aulas de Química. Na pesquisa qualitativa, os dados coletados são analisados indutivamente, tendo o processo e seu significado como os focos principais de análise (PRODANOV; FREITAS, 2013). Quanto ao procedimento técnico, o estudo caracterizou-se como uma pesquisa-ação, uma vez que necessitou do envolvimento ativo do pesquisador e da ação dos sujeitos envolvidos no problema, apresentando, portanto, caráter intervencionista (PICHETH; CASSANDRE; THIOLLENT, 2016).

A investigação teve como público-alvo 39 estudantes do $2^{\circ}$ ano $D$ do Ensino Médio da EREM Antônio Padilha. Para o desenvolvimento do estudo, inicialmente, aplicou-se um pré-teste para levantar os conhecimentos prévios dos estudantes. Posteriormente, executaram-se ações interventivas, durante os meses de fevereiro e março de 2021, perfazendo um total de 50 horasaula de atividades que envolveram a interação entre o residente e os alunos da turma.

Em busca de alcançar o objetivo proposto, adotaram-se metodologias de ensino para atender às necessidades encontradas no âmbito da sala de aula, considerando os seguintes conteúdos programáticos da disciplina de Química: i. matéria e energia; ii. fases de agregação da matéria; iii. Mudanças de estados físicos da matéria; iv. substâncias e misturas; v. métodos de separação de misturas; vi. introdução ao laboratório; vii. segurança em laboratório; viii vidrarias e equipamentos básicos; e ix. conteúdos complementares.

Embora os alunos atendidos estivessem cursando o $2^{\circ}$ ano, os conteúdos do primeiro bimestre de 2021 foram iguais aos do $1^{\circ}$ ano, conforme orientações da Secretaria de Educação de Pernambuco, em virtude das consequências causadas pela pandemia do covid-19 na educação. Tal iniciativa foi uma tentativa de reforçar os conteúdos e amenizar os atrasos e as perdas que a pandemia causou no contexto educacional da rede estadual de ensino.

Visou-se a relacionar os conteúdos com o tema gerador água, trabalhando, por exemplo, a água como fonte de energia, o ciclo hidrológico, as propriedades da água como solvente, a poluição, o desperdício, os riscos de escassez e o tratamento de água. Para tanto, propôs-se trabalhar a utilização de vídeos, de música, de jogos, de página educativa na rede social Instagram, de aulas virtuais via Google Meet, de simulador de experimentos, dentre outras atividades. Pretendeu-se, de maneira adicional, desenvolver ações que estimulassem a autonomia na aprendizagem discente.

O desenvolvimento das atividades planejadas seguiu o formato de ensino híbrido, uma modalidade que alia o ensino presencial e o remoto, envolvendo encontros síncronos e atividades assíncronas, possibilitando uma aprendizagem mediada, em parte, por intermédio de ferramentas tecnológicas (BERTHOLDO NETO, 2017). O Quadro 1 apresenta os métodos estabelecidos para a execução das intervenções, de acordo com os conteúdos programáticos e a temática geradora.

Quadro 1 - Descrição dos métodos e dos conteúdos trabalhados durante a pesquisa de intervenção com alunos do $2^{\circ}$ ano do Ensino Médio da EREM Antônio Padilha, perfazendo 50 horas-aula.

\begin{tabular}{|c|c|c|c|}
\hline Metodologia e formato de ensino & Conteúdo & $\begin{array}{c}\text { Relação com o } \\
\text { tema gerador }\end{array}$ & Duração \\
\hline Apresentação do projeto (presencial e & Introdução à Química & Introdução à & $10 \mathrm{~h}$ \\
\hline
\end{tabular}


RIBEIRO, L. C., DOS ANJOS, V. H. A. e DOS ANJOS, D.S.C.

A água como tema gerador do conhecimento químico: construindo um ensino-aprendizado contextual e cidadão no ensino de Química

\begin{tabular}{|c|c|c|c|}
\hline $\begin{array}{l}\text { remoto síncrono), aplicação de pré-teste } \\
\text { (remoto assíncrono), introdução aos } \\
\text { conteúdos (presencial e remoto assíncrono), } \\
\text { exibição de vídeo sobre água (presencial e } \\
\text { remoto assíncrono) e resolução e correção } \\
\text { de exercícios (remoto assíncrono) }\end{array}$ & $\begin{array}{l}\text { e apresentação do } \\
\text { tema gerador }\end{array}$ & temática & \\
\hline $\begin{array}{l}\text { Sala de aula invertida - leitura de material } \\
\text { (remoto assíncrono), interpretação da } \\
\text { música “Planeta Água” de Guilherme } \\
\text { Arantes (presencial e remoto síncrono), aula } \\
\text { dialogada (presencial e remoto síncrono), } \\
\text { elaboração e postagem de mapa mental em } \\
\text { página no Instagram (remoto assíncrono) }\end{array}$ & Matéria e energia & $\begin{array}{l}\text { Água como matéria } \\
\text { e fonte de energia, } \\
\text { poluição, uso } \\
\text { exagerado e riscos } \\
\text { de escassez }\end{array}$ & $12 \mathrm{~h}$ \\
\hline $\begin{array}{l}\text { Sala de aula invertida - vídeo sobre o ciclo } \\
\text { da água e leitura de material (remoto } \\
\text { assíncrono), aula dialogada (remoto } \\
\text { síncrono), jogo de palavras cruzadas } \\
\text { (remoto assíncrono), produção de material } \\
\text { para página no Instagram (remoto } \\
\text { assíncrono) e atendimento ao aluno (remoto } \\
\text { síncrono) }\end{array}$ & $\begin{array}{c}\text { Fases de agregação da } \\
\text { matéria e mudanças } \\
\text { de estado físico }\end{array}$ & $\begin{array}{l}\text { Estados físicos da } \\
\text { água e ciclo } \\
\text { hidrológico }\end{array}$ & $8 \mathrm{~h}$ \\
\hline $\begin{array}{l}\text { Jogo de perguntas - Kahoot (remoto } \\
\text { síncrono), aula dialogada (remoto síncrono), } \\
\text { atividade avaliativa (remoto assíncrono) e } \\
\text { atendimento ao aluno (remoto síncrono) }\end{array}$ & $\begin{array}{l}\text { Substâncias e } \\
\text { misturas }\end{array}$ & $\begin{array}{c}\text { Água como solvente } \\
\text { universal e suas } \\
\text { propriedades }\end{array}$ & $10 \mathrm{~h}$ \\
\hline $\begin{array}{l}\text { Apreciação do vídeo do canal Manual do } \\
\text { Mundo no YouTube (remoto assíncrono), } \\
\text { sala de aula invertida - experimentação } \\
\text { (remoto assíncrono), atendimento ao aluno } \\
\text { (remoto síncrono), aula dialogada (remoto } \\
\text { síncrono), e produção de material para } \\
\text { página no Instagram (remoto assíncrono) }\end{array}$ & $\begin{array}{l}\text { Métodos de separação } \\
\text { de misturas }\end{array}$ & Tratamento de água & $6 \mathrm{~h}$ \\
\hline $\begin{array}{c}\text { Aula dialogada (remoto síncrono) e } \\
\text { aplicação de pós-teste (remoto assíncrono). }\end{array}$ & $\begin{array}{l}\text { Introdução ao } \\
\text { laboratório, } \\
\text { segurança em } \\
\text { laboratório, vidrarias } \\
\text { e equipamentos } \\
\text { básicos }\end{array}$ & $\begin{array}{l}\text { Lavagem de } \\
\text { vidrarias }\end{array}$ & $4 \mathrm{~h}$ \\
\hline
\end{tabular}

Fonte: própria (2021).

Os dados foram coletados por meio de observação estruturada durante a realização de todas as atividades, por meio da qual "[...] o observador sabe o que procura, planeja essa busca e sistematiza as informações” (ZANELLA, 2013, p. 121). Além disso, aplicou-se um pós-teste para verificar o aprendizado construído, bem como para avaliar e compreender, sob a perspectiva dos discentes, a importância das ações desenvolvidas. Por fim, os dados foram analisados e discutidas considerando os estudos já desenvolvidos sobre a temática.

\section{Resultados e discussão}

Inicialmente, observou-se que a apresentação das atividades previstas no projeto de intervenção foi crucial para despertar, nos estudantes, a curiosidade e a empolgação para participar das ações. Nesse momento, a apreciação do vídeo Você já tomou $\mathrm{H}_{2} \mathrm{O}$ ? (DESENROLADO, 2018) mostrou a importância do conhecimento sobre a água, uma vez que os entrevistados, no vídeo, não 
RIBEIRO, L. C., DOS ANJOS, V. H. A. e DOS ANJOS, D.S.C.

A água como tema gerador do conhecimento químico: construindo um ensino-aprendizado contextual e cidadão no ensino de Química

sabiam que $\mathrm{H}_{2} \mathrm{O}$ é a fórmula molecular da água, chegando, inclusive, a pensar ou afirmar que seria uma droga ilícita.

$\mathrm{Na}$ análise das respostas do pré-teste, evidenciou-se que, embora o conteúdo já tivesse sido trabalhado pelo professor regente no ano anterior, alguns estudantes acertaram menos de $50 \%$ das questões relacionadas aos conteúdos programáticos de Química. No entanto, por se tratar de conhecimentos prévios, esperava-se um resultado semelhante ao obtido. O Quadro 2 apresenta os dados referentes às questões do pré-teste relacionadas aos assuntos envolvidos no projeto.

Quadro 2 - Respostas dos estudantes às questões afirmativas do pré-teste referentes aos conteúdos químicos contemplados pelo projeto de intervenção.

\begin{tabular}{|c|c|c|c|}
\hline $\begin{array}{l}\text { Código da } \\
\text { questão } \\
\text { afirmativa }\end{array}$ & Afirmativa & Resposta correta & $\begin{array}{c}\text { Porcentagem } \\
\text { de acertos }\end{array}$ \\
\hline $\mathrm{A} 01$ & $\begin{array}{c}\text { Matéria é tudo o que possui massa e ocupa lugar no } \\
\text { espaço. }\end{array}$ & Verdadeira & $90 \%$ \\
\hline A02 & $\begin{array}{c}\text { No estado gasoso, as partículas estão mais unidas e } \\
\text { possuem menor grau de agitação do que no estado } \\
\text { sólido. }\end{array}$ & Falsa & $80 \%$ \\
\hline $\mathrm{A} 03$ & $\begin{array}{l}\text { A naftalina, à temperatura e à pressão ambientes, } \\
\text { passa do estado sólido para o gasoso. Esse processo é } \\
\text { denominado de sublimação. }\end{array}$ & Verdadeira & $70 \%$ \\
\hline A04 & $\begin{array}{l}\mathrm{H}_{2} \mathrm{O} \text { é uma substância simples, enquanto } \mathrm{O}_{2} \text { é uma } \\
\text { substância composta. }\end{array}$ & Falsa & $95 \%$ \\
\hline A05 & O ar atmosférico é uma mistura homogênea. & Verdadeira & $75 \%$ \\
\hline A06 & $\begin{array}{l}\text { Em uma mistura de areia e limalhas de ferro os } \\
\text { componentes podem ser separados por meio de } \\
\text { separação magnética. }\end{array}$ & Verdadeira & $65 \%$ \\
\hline A07 & $\begin{array}{l}\text { As substâncias puras apresentam ponto de fusão e ponto } \\
\text { de ebulição constantes. }\end{array}$ & Verdadeira & $45 \%$ \\
\hline A08 & $\begin{array}{l}\text { O funil indicado para separar uma mistura heterogênea } \\
\text { de líquidos imiscíveis é igual ao funil usado em uma } \\
\text { filtração simples. }\end{array}$ & Falsa & $85 \%$ \\
\hline A09 & $\begin{array}{c}\text { No laboratório de Química, é preciso estar atento às } \\
\text { normas de segurança e ao manuseio correto dos } \\
\text { equipamentos. }\end{array}$ & Verdadeira & $80 \%$ \\
\hline
\end{tabular}

Fonte: própria (2021).

Das questões afirmativas referentes aos conteúdos químicos, somente A01, A03, A05, A06, A07 e A09 estão corretas. Todavia, as porcentagens indicam que um número expressivo de alunos respondeu incorretamente a algumas questões. Conforme observado em A07, 45\% dos estudantes não interpretaram corretamente a afirmação. Portanto, entendeu-se a necessidade de atuar de forma mais atenciosa na abordagem desses conceitos.

Além disso, constatou-se, por meio das respostas do questionário pré-teste, que os discentes apresentavam conhecimento prévio significativo a respeito do tema gerador. Nessa perspectiva, entendeu-se que tal conhecimento deve-se à presença desse tema na rotina dos alunos, embora não seja tratado com uma linguagem formal da Química. O Quadro 3 apresenta os dados referentes às respostas dadas às questões afirmativas do pré-teste relacionadas ao tema gerador água.

Quadro 3 - Respostas dos estudantes às questões afirmativas do pré-teste referentes ao tema gerador do projeto de intervenção.

\begin{tabular}{|c|c|c|c|}
\hline Código da & Afirmativa & Resposta correta & Porcentagem \\
\hline
\end{tabular}


RIBEIRO, L. C., DOS ANJOS, V. H. A. e DOS ANJOS, D.S.C.

A água como tema gerador do conhecimento químico: construindo um ensino-aprendizado contextual e cidadão no ensino de Química

\begin{tabular}{|c|c|c|c|}
\hline $\begin{array}{l}\text { questão } \\
\text { afirmativa }\end{array}$ & & & de acertos \\
\hline B01 & A água é um recurso essencial à vida. & Verdadeira & $90 \%$ \\
\hline B02 & $\begin{array}{c}\text { A maior parte da água existente no planeta é doce e } \\
\text { apropriada para o consumo humano. }\end{array}$ & Falsa & $70 \%$ \\
\hline B03 & $\begin{array}{c}\text { A maior parte da superfície da Terra está coberta por } \\
\text { água doce. }\end{array}$ & Falsa & $75 \%$ \\
\hline B04 & A fórmula molecular da água é $\mathrm{H}_{2} \mathrm{O}$. & Verdadeira & $50 \%$ \\
\hline B05 & Há previsão de crise hídrica no planeta. & Verdadeira & $85 \%$ \\
\hline B06 & $\begin{array}{c}\text { Os riscos de escassez hídrica são impulsionados em } \\
\text { maior parte pela ação natural do meio ambiente e em } \\
\text { menor parte pela ação humana. }\end{array}$ & Falsa & $70 \%$ \\
\hline B07 & $\begin{array}{l}\text { O desperdício e a poluição são fatores que impulsionam } \\
\text { a redução da quantidade de água potável. }\end{array}$ & Verdadeira & $65 \%$ \\
\hline B08 & $\begin{array}{c}\text { O tratamento de água } 100 \% \text { adequado pode ser } \\
\text { realizado em casa, sem riscos de danos à saúde após o } \\
\text { consumo do líquido tratado. }\end{array}$ & Falsa & $70 \%$ \\
\hline
\end{tabular}

Fonte: própria (2021).

Das questões afirmativas referentes ao tema gerador, apenas B01, B04, B05 e B07 são verdadeiras. Contudo, percebeu-se que, mesmo nas afirmações de discussões comuns do dia a dia, tais como B02, B04, B06, B07 e B08, alguns estudantes marcaram a resposta incorreta. Importa destacar que, de acordo com B04, apenas $50 \%$ dos alunos sabiam que $\mathrm{H}_{2} \mathrm{O}$ é a fórmula da molécula da água.

Considerando os resultados do pré-teste, a introdução aos conteúdos químicos constituintes do projeto de intervenção foi fundamental para revisar os principais conceitos trabalhados na disciplina durante o ano letivo de 2020. 0 aproveitamento da revisão foi evidenciado pelas respostas às questões da atividade assíncrona referente à aula. Durante a resolução, os alunos procuraram residente para dirimir dúvidas e, no momento da correção em uma aula remota, houve interação entre o residente e os estudantes.

$\mathrm{Na}$ aula específica para discutir somente o primeiro conteúdo, matéria e energia, a apreciação e a interpretação da música Planeta Água, de Guilherme Arantes, estimularam discussões sobre a importância da água para a manutenção da vida, destacando a ação humana como principal responsável pela poluição, pelo desperdício e, consequentemente, pelos riscos crescentes de escassez hídrica. Essas considerações estão de acordo com as expostas por Silva, Dantas Filho e Silva (2020), ao pontuarem que o uso da música diversifica a prática docente, dinamizando as aulas e abrindo espaços oportunos para debater os conteúdos ensinados.

0 trabalho com mapas mentais mostrou-se eficiente no processo educativo, pois estimulou os alunos a estudarem, a sintetizarem e a organizarem as informações centrais referentes ao estudo das propriedades e das transformações da matéria. Nesse sentido, concorda-se com Simplício, Sousa e Anjos (2020), uma vez que é uma atividade adequada para introduzir, para revisar ou para concluir um conteúdo, trabalhando a síntese de ideias a partir da organização de elementos-chave.

A Figura 1 apresenta um dos mapas mentais elaborados.

Figura 1 - Mapa mental sobre propriedades e sobre transformações da matéria elaborado por estudante. 


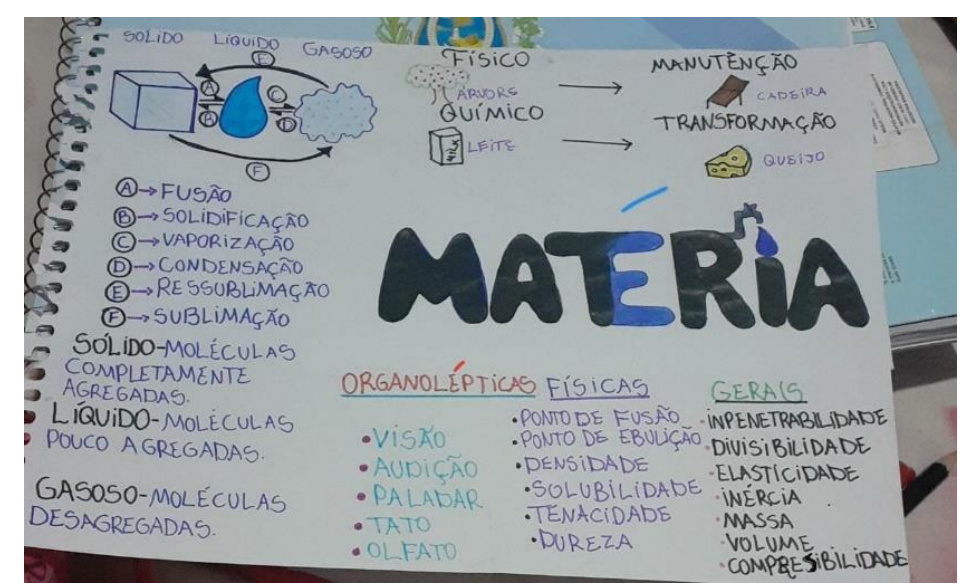

Fonte: própria (2021).

$\mathrm{Na}$ abordagem do segundo conteúdo, estados físicos da matéria, presenciou-se elevada participação dos estudantes, em decorrência do estudo antecipado, mediante a disponibilização de material para leitura e a indicação do vídeo O Ciclo da Água (ALBERT, 2020). As respostas dadas à cruzadinha, após a aula, e os materiais produzidos, desenhos, esquemas e mapas mentais, evidenciaram que os estudantes conseguiram compreender o conteúdo e aplicar os conceitos considerando as mudanças de estado físico ocorrentes no ciclo hidrológico. A Figura 2 apresenta um dos materiais elaborados.

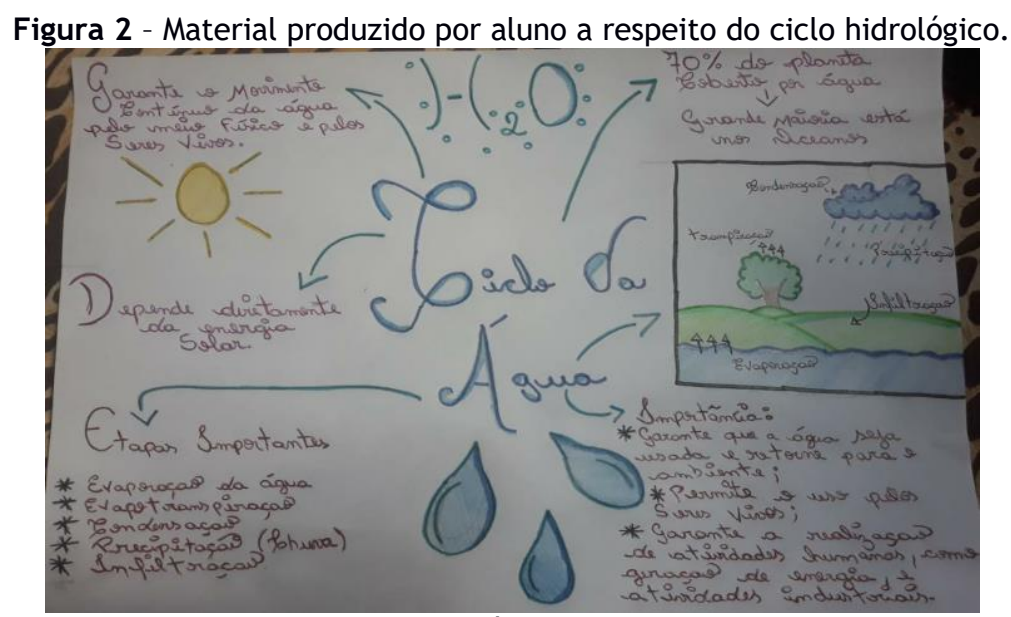

Fonte: própria (2021).

Nesse sentido, percebeu-se que tal resultado é consequência da aplicação da sala de aula invertida, que modificou a ideia tradicional de ensino, a partir da qual o aluno somente tem contato com o conteúdo por intermédio da explicação do professor em sala de aula. Com esse método de sala de aula invertida, o aluno tem acesso aos conteúdos com antecedência para que o tempo em sala seja otimizado, oportunizando, também, autonomia e participação no decorrer do estudo (SILVA; MOURA, 2020).

No estudo do terceiro conteúdo, substâncias e misturas, o jogo de perguntas e de respostas (quiz), utilizando a plataforma Kahoot, estimulou a aprendizagem de forma dinâmica e participativa. Nessa atividade, foi possível trabalhar diferentes conceitos químicos levando-se em 
RIBEIRO, L. C., DOS ANJOS, V. H. A. e DOS ANJOS, D.S.C.

A água como tema gerador do conhecimento químico: construindo um ensino-aprendizado contextual e cidadão no ensino de Química

consideração os parâmetros: tempo, competitividade e conhecimento. Segundo Messeder Neto e Moradillo (2017), a dinâmica do jogo permite que o discente avalie os seus conhecimentos e crie/fortaleça a afinidade com a disciplina de Química. A Figura 3 mostra a aula realização do quiz durante aula remota síncrona.

Figura 3 - Aula remota síncrona com aplicação de quiz utilizando o Kahoot.

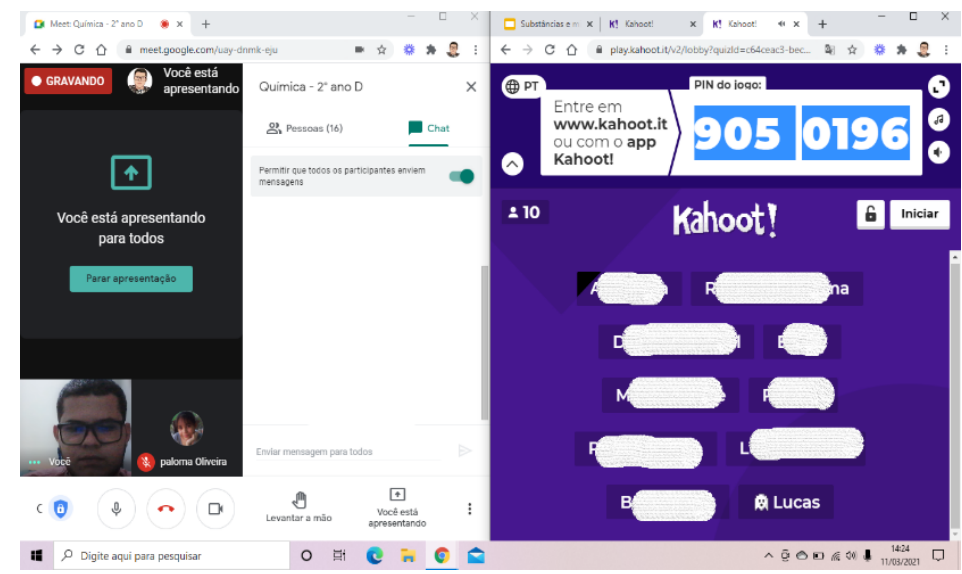

Fonte: própria (2021).

No quarto e no quinto conteúdos, separação de misturas e laboratório, respectivamente, os alunos foram desafiados, sob orientação do residente, a construir, em casa, um filtro simulador do tratamento de água, utilizando materiais alternativos. Como resultado, foram produzidos filtros capazes de mudar a cor de água suja (água com terra) e deixá-la nitidamente transparente, mas importa citar que a água não foi consumida. Os alunos utilizaram, em substituição às vidrarias necessárias, garrafas de polietileno tereftalato (PET), conforme mostra a Figura 4.

Figura 4 - Experimento de simulação de tratamento de água realizado por estudante.

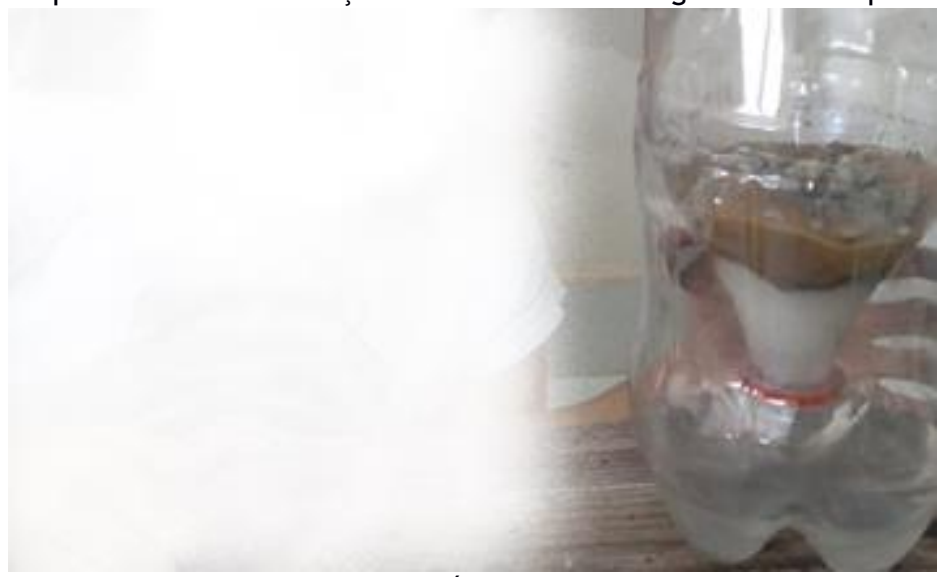

Fonte: própria (2021).

$\mathrm{Na}$ aula destinada à abordagem desses dois conteúdos, comparam-se os procedimentos adotados na construção do filtro caseiro com os procedimentos que são utilizados nas estações de tratamento de água e apresentaram-se as vidrarias e os equipamentos que seriam utilizados caso o 
RIBEIRO, L. C., DOS ANJOS, V. H. A. e DOS ANJOS, D.S.C.

A água como tema gerador do conhecimento químico: construindo um ensino-aprendizado contextual e cidadão no ensino de Química

experimento fosse realizado em um laboratório de Química. Alguns estudantes ficaram surpresos ao saberem que os processos de separação de misturas são aplicados ao tratamento de água. 0 procedimento real que ocorre nas estações de tratamento de água foi visto no vídeo Como é Feito o Tratamento de Água (MUNDO, 2017).

Os resultados de aprendizagem investigativa oportunizados pela experimentação vão ao encontro de Gabriel, Rodríguez e Fluente (2016), ao considerarem que, na Química, a utilização de experimentos se apresenta como uma metodologia de ensino capaz de estimular os alunos a desenvolverem elementos essenciais à prática investigativa: comparar, questionar, sugerir, criticar e traçar conclusões.

Os registros dos materiais produzidos pelos estudantes foram publicados em uma página educativa criada na rede social Instagram, @contextualizandoaquimica, conforme mostra a Figura 5, com o objetivo de compartithar as atividades desenvolvidas. Verificou-se que tal iniciativa colaborou para obter resultados positivos, uma vez que os discentes construíram a visão de que os materiais poderiam ser visualizados por diversas pessoas que utilizam a rede social e, portanto, necessitavam de dedicação e de criatividade, a fim de garantir a qualidade em termos de aparência e de conteúdo.

Figura 5 - Página educativa @contextualizandoaquimica criada na rede social Instagram.

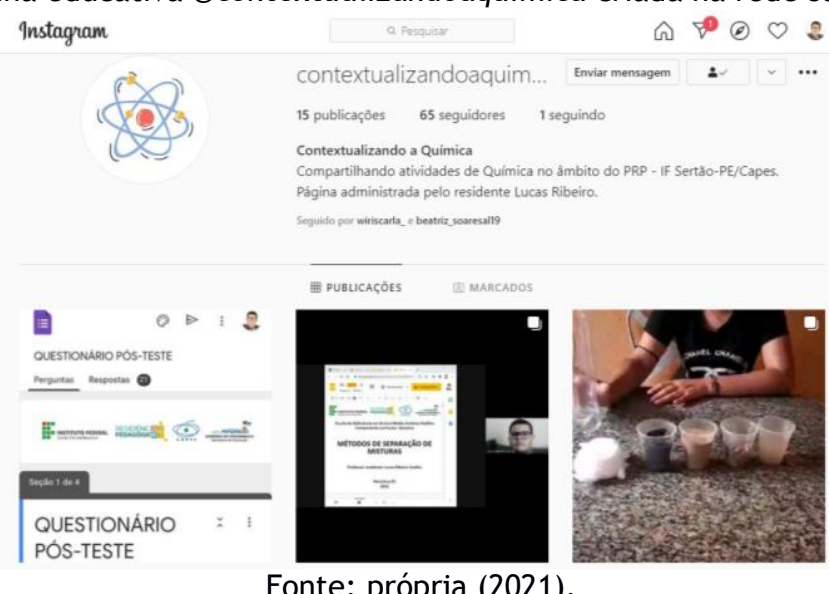

Fonte: própria (2021).

Nesse contexto, ratificou-se, com a análise do questionário pós-teste, o aproveitamento e o aprendizado dos conteúdos químicos e do tema gerador trabalhados no projeto de intervenção, uma vez que todos os estudantes acertaram mais de $70 \%$ das questões, um aspecto não observado no pré-teste. 0 Quadro 4 apresenta os dados referentes às questões do pós-teste relacionadas aos conteúdos abordados.

Quadro 4 - Respostas dos estudantes às questões afirmativas do pós-teste referentes aos conteúdos químicos contemplados pelo projeto de intervenção.

\begin{tabular}{|c|c|c|c|}
\hline $\begin{array}{c}\text { Código da } \\
\text { questão } \\
\text { afirmativa }\end{array}$ & Afirmativa & Resposta correta & $\begin{array}{c}\text { Porcentagem } \\
\text { de acertos }\end{array}$ \\
\hline C01 & Matéria, objeto de estudo da Química, é tudo o que possui & Verdadeira & $100 \%$ \\
\hline
\end{tabular}


RIBEIRO, L. C., DOS ANJOS, V. H. A. e DOS ANJOS, D.S.C.

A água como tema gerador do conhecimento químico: construindo um ensino-aprendizado contextual e cidadão no ensino de Química

\begin{tabular}{|c|c|c|c|}
\hline & massa e ocupa lugar no espaço. & & \\
\hline $\mathrm{CO2}$ & A água é matéria e fonte de energia. & Verdadeira & $100 \%$ \\
\hline $\mathrm{CO3}$ & $\begin{array}{l}\text { Os líquidos possuem volume definido e forma indefinida, } \\
\text { enquanto os sólidos possuem volume e forma definidos. }\end{array}$ & Verdadeira & $75 \%$ \\
\hline $\mathrm{CO4}$ & $\begin{array}{l}\text { No ciclo hidrológico, são observadas as seguintes mudanças } \\
\text { de estado físico: evaporação e condensação. }\end{array}$ & Verdadeira & $90 \%$ \\
\hline C05 & $\begin{array}{l}\text { As moléculas de água no estado de vapor estão mais } \\
\text { próximas umas das outras do que no estado líquido. }\end{array}$ & Falsa & $80 \%$ \\
\hline C06 & $\begin{array}{l}\text { As substâncias simples, como o } \mathrm{O}_{2} \text { e o } \mathrm{N}_{2} \text {, são formadas por } \\
\text { átomos de um mesmo elemento químico. }\end{array}$ & Verdadeira & $75 \%$ \\
\hline $\mathrm{CO7}$ & $\begin{array}{l}\text { A água, por ser uma substância pura, apresenta pontos de } \\
\text { fusão e de ebulição constantes. }\end{array}$ & Verdadeira & $85 \%$ \\
\hline C08 & $\begin{array}{l}\text { Os componentes de uma solução aquosa de cloreto de } \\
\text { sódio podem ser separados por destilação simples. }\end{array}$ & Verdadeira & $80 \%$ \\
\hline C09 & $\begin{array}{l}\text { O funil indicado para separar uma mistura heterogênea } \\
\text { de líquidos imiscíveis é conhecido como funil de } \\
\text { decantação e é diferente do funil usado em uma filtração } \\
\text { simples. }\end{array}$ & Verdadeira & $90 \%$ \\
\hline C10 & $\begin{array}{c}\text { O jaleco só precisa ser usado em um laboratório de } \\
\text { Química quando a própria pessoa está realizando algum } \\
\text { procedimento experimental. Para somente observar } \\
\text { algum experimento, o jaleco se torna um item } \\
\text { desnecessário dentro do laboratório. }\end{array}$ & Falsa & $75 \%$ \\
\hline
\end{tabular}

Fonte: própria (2021).

Observou-se que as questões C01 e C02 foram respondidas corretamente por 100\% dos alunos e as demais tiveram acertos expressivos. Importa citar que a questão C07, a qual $85 \%$ dos participantes responderam corretamente, é semelhante à A07 do pré-teste, que apenas $45 \%$ dos estudantes acertaram. Portanto, houve uma evolução significativa durante as intervenções na disciplina de Química.

Tratando-se da temática geradora, percebeu-se que o tratamento do tema a partir de uma linguagem química propiciou agregar mais aprendizado aos conhecimentos prévios dos estudantes diagnosticados no pré-teste. 0 Quadro 5 resume os dados obtidos por meio das questões do pósteste referentes à água como tema gerador das intervenções.

Quadro 5 - Respostas dos estudantes às questões afirmativas do pós-teste referentes ao tema gerador do projeto de intervenção.

\begin{tabular}{|c|c|c|c|}
\hline $\begin{array}{l}\text { Código da } \\
\text { questão } \\
\text { afirmativa }\end{array}$ & Afirmativa & Resposta correta & $\begin{array}{l}\text { Porcentagem } \\
\text { de acertos }\end{array}$ \\
\hline D01 & $\begin{array}{c}\text { A maior parte da água existente no planeta é salgada e } \\
\text { apropriada para o consumo humano. }\end{array}$ & Falsa & $80 \%$ \\
\hline D02 & $\begin{array}{c}\text { A maior parte da superfície da Terra está coberta por água } \\
\text { salgada. }\end{array}$ & Verdadeira & $95 \%$ \\
\hline D03 & $\begin{array}{l}\text { Os riscos de escassez hídrica são impulsionados pela ação } \\
\text { humana irresponsável. }\end{array}$ & Verdadeira & $85 \%$ \\
\hline D04 & $\begin{array}{l}\text { As mudanças de estado físico observadas no ciclo } \\
\text { hidrológico são fenômenos químicos, e não físicos. }\end{array}$ & Falsa & $75 \%$ \\
\hline D05 & A fórmula molecular da água é $\mathrm{H}_{2} \mathrm{O}$. & Verdadeira & $100 \%$ \\
\hline
\end{tabular}

Fonte: própria (2021).

Comparando a questão D05, com 100\% de acertos, com a questão B04 presente no pré-teste, cuja porcentagem de acertos foi $50 \%$, notou-se que todos os estudantes, depois das intervenções, passaram a conhecer a água não apenas pelo seu nome comum, mas pela sua fórmula química 
RIBEIRO, L. C., DOS ANJOS, V. H. A. e DOS ANJOS, D.S.C.

A água como tema gerador do conhecimento químico: construindo um ensino-aprendizado contextual e cidadão no ensino de Química

molecular. Além disso, verificou-se que houve evolução conceitual quanto à quantidade de água disponível para o consumo humano e aos fatores que impulsionam os riscos de escassez hídrica.

No questionário de satisfação, $100 \%$ dos estudantes afirmaram que as atividades desenvolvidas ajudaram na aprendizagem e foram um diferencial nas aulas de Química. 0 Gráfico 1 apresenta as respostas dos estudantes quando questionados qual(is) atividade(s) desenvolvida(s) nas aulas despertou(ram) mais gosto durante a participação.

Gráfico 1 - Atividades que os estudantes apresentaram mais afinidade durante a participação.

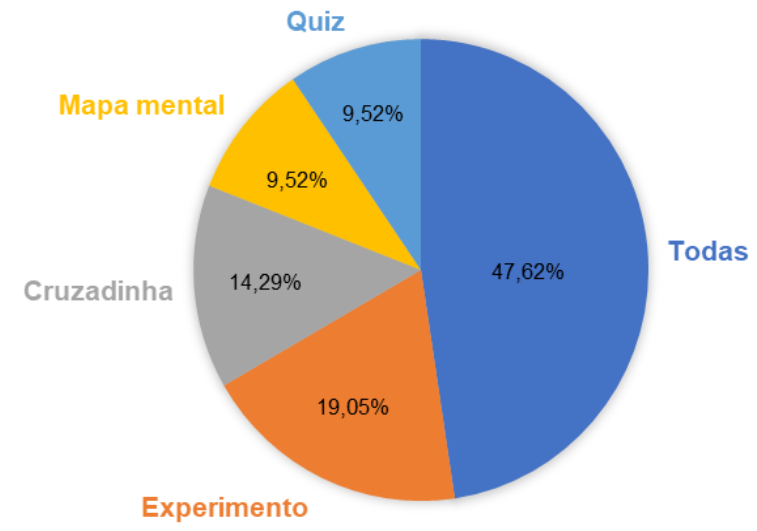

Fonte: própria (2021).

A maioria dos alunos participantes, 47,62\%, afirmou que teve afinidade e gostou de todas as atividades realizadas. Em segundo lugar, 19,05\% dos discentes gostaram mais do experimento de simulação de tratamento de água. Outros, uma minoria, despertaram mais gosto por outras atividades específicas: cruzadinha, mapa mental e quiz. Isso demonstra que a diversificação de métodos é importante, uma vez que oportuniza trabalhar ações que despertem o interesse em todo o público da sala de aula física e/ou virtual.

Tais atividades oportunizaram a participação ativa dos alunos na construção do conhecimento. De acordo com Silva e Moura (2020), as metodologias ativas tornam os estudantes os principais protagonistas do processo de ensino-aprendizagem. Além disso, na perspectiva de ensino por investigação apresentado nesse estudo, as metodologias ativas são, também, métodos de ensino investigativo.

Levando-se em consideração a concepção de Simplício, Sousa e Anjos (2020), os impactos positivos das metodologias ativas no processo educativo são nítidos. Quando utilizados de maneira adequada e globalizada, tais métodos possibilitam êxito no ensino. Ademais, o campo das metodologias ativas é vasto, pois existem métodos de aplicação prática, lúdica, dinâmica e contextualizada capazes de favorecer o ensino e a aprendizagem.

Para que essas metodologias possam ser consideradas eficientes na sua aplicação didática, é necessário que haja organização e articulação bem-elaboradas entre os assuntos do currículo da disciplina e as atividades, de modo a atingir as premissas das metodologias ativas. Outrossim, é importante que o docente trabalhe as possíveis dúvidas apresentadas pelos discentes (SANT'ANA; 
RIBEIRO, L. C., DOS ANJOS, V. H. A. e DOS ANJOS, D.S.C.

A água como tema gerador do conhecimento químico: construindo um ensino-aprendizado contextual e cidadão no ensino de Química

CASTRO, 2019). Nesse sentido, os horários disponibilizados para atendimento aos alunos favoreceram o êxito dos métodos adotados nas intervenções.

Importa destacar que esses resultados não são decorrentes apenas da utilização de atividades diversificadas. Os debates promovidos nas aulas, a partir do tema gerador água, atribuíram importância e significados práticos aos conteúdos estudados. As situações reais do cotidiano proporcionam discussões que contextualizam e atribuem aplicabilidade aos conteúdos e aos fenômenos explorados na disciplina de Química.

O questionário de satisfação permitiu constatar, também, que 100\% dos alunos afirmaram que o tema gerador facilitou o entendimento dos conteúdos e que as aulas influenciaram e ajudaram a refletir e a decidir colocar em prática ações em a favor da preservação da água. 0 Quadro 6 apresenta algumas das respostas dadas à seguinte questão: na sua perspectiva, trabalhar o tema água foi importante?

Quadro 6 - Respostas dos estudantes à questão: na sua perspectiva, trabalhar o tema água foi importante?

\begin{tabular}{|c|}
\hline "Sim, pois nos ensinou a importância". \\
\hline “Sim, porque podemos saber mais sobre como a água é tratada". \\
\hline $\begin{array}{c}\text { “Porque a água é o principal meio de vida e aprofundar nesse assunto foi interessante, pois agora sabemos } \\
\text { que água pode mudar para vários estados [físicos] e tem várias características". }\end{array}$ \\
\hline "Sim, porque a água é um recurso importante em todos os fatores". \\
\hline "Sim, pois é algo importante para o nosso dia a dia. A água é utilizada para quase tudo". \\
\hline $\begin{array}{c}\text { "O tema [...] permite }[\ldots] \text { problematizar situações importantes para que os alunos a interpretem, de maneira } \\
\text { que os conceitos químicos possam auxiliar no entendimento de problemas, propiciando [...] a formação de um } \\
\text { estudante responsável". }\end{array}$ \\
\hline $\begin{array}{c}\text { "Sim... é legal saber [...] como ocorre todo o processo hidrológico e de tratamento de água que consumimos } \\
\text { com muita frequência". }\end{array}$ \\
\hline "Sim, aprendi muito como não desperdiçar água". \\
\hline $\begin{array}{c}\text { "Sim, aprendi mais sobre como trabalhar os estados físicos e como ocorre todo } \\
\text { água chegue a nossas casas". }\end{array}$ \\
\hline
\end{tabular}

Fonte: própria (2021).

A partir dos comentários, verificou-se que, sob a perspectiva dos participantes, trabalhar o tema água foi essencial ao processo de ensino e de aprendizagem de Química, auxiliando a formação de cidadãos críticos e reflexivos. Nesse sentido, a inserção da água como tema gerador no ensino de Química contextualizou as aulas, tornando-se um diferencial na abordagem dos conteúdos, aproximando o indivíduo de sua realidade.

Evidenciou-se que os alunos demonstraram ter conhecimento sobre a importância, a qualidade e a potabilidade da água, bem como sensibilização em relação ao mau uso e ao desperdício. Portanto, as ações interventivas desenvolvidas promoveram a construção de um ensinoaprendizado, além de contextual e cidadão, no ensino de Química. Essas considerações vão ao encontro de Gouve et al. (2015), ao apontarem a relevância dessa temática no ensino de ciências.

Por isso, Santos e Rodrigues (2018) pontuam que os recursos hídricos são bastante utilizados na prática pedagógica do processo de ensino-aprendizagem de Química, mas não significa que a temática deixou de ser inovadora. Isso indica que o tema continua sendo atual, inovador e pertinente ao processo educativo, pois, desse modo, atinge-se um público maior e possibilita 
RIBEIRO, L. C., DOS ANJOS, V. H. A. e DOS ANJOS, D.S.C

A água como tema gerador do conhecimento químico: construindo um ensino-aprendizado contextual e cidadão no ensino de Química

resolver duas problemáticas: a constante descontextualização dos conteúdos químicos e a aceleração das previsões de crise hídrica.

Nessa pesquisa, o desenvolvimento de diferentes metodologias ativas, trabalhando os conteúdos de maneira contextualizada, tornou o processo educativo, de fato, centrado na aprendizagem do aluno. Nessa abordagem, de acordo com as considerações expostas por Pinheiro e Batista (2018), o estudante se torna agente ativo para atuar e para interferir nas diversas situações que perpassam a vida em sociedade, alcançando-se, assim, um ensino que integra a contextualização, a investigação e a formação para o exercício da cidadania.

Os achados desse estudo corroboram com Silva, Sousa e Anjos (2020, p. 566), uma vez que os métodos utilizados valorizaram a Química “[...] como responsável pelo desenvolvimento de ações adequadas para a preservação dos recursos naturais, além de uma disciplina crítica, interativa e divertida, capaz de instigar nos alunos a busca do seu próprio conhecimento e a se tornarem bons cidadãos". Assim, confirma-se a ideia de Coelho, Rodrigues e Sá-Silva (2020) acerca da importância de ações de perspectiva interventiva para solucionar problemas diagnosticados no ensino de Química.

\section{Conclusões}

Nesse estudo, os resultados obtidos mediante implementação e avaliação do projeto de intervenção responderam à problemática estruturada a partir de observações na EREM Antônio Padilha, promovendo aos alunos participantes a construção do conhecimento químico de maneira contextual e cidadã, considerando as implicações das metodologias ativas e a pertinência da abordagem do tema água adotado para conduzir os debates durante o processo educativo.

As metodologias ativas utilizadas mostraram-se eficientes e como possibilidades para a prática do ensino de Química dinâmico e prazeroso para os estudantes. Além disso, a inserção da água como temática norteadora do estudo dos conteúdos programáticos do componente curricular no ensino médio apresentou-se potencialmente capaz de contextualizar o ensino, atribuindo aplicabilidade aos conceitos científicos.

Nesse contexto, ficou evidente que as práticas educacionais desenvolvidas durante as intervenções oportunizaram aprendizagens significativas no processo de ensino e de aprendizagem de Química e auxiliaram à formação de cidadãos críticos e reflexivos frente à problemática dos recursos hídricos apresentada, considerando que os sujeitos necessitam ser capazes de intervir de modo responsável no meio onde estão inseridos.

Portanto, acredita-se que as ideias apresentadas e discutidas nesse escrito servem de embasamento teórico para pesquisadores do campo da educação e para auxiliar os professores de Química e de outros componentes curriculares a desenvolverem práticas pedagógicas inovadoras, com potencial para melhorar os resultados de aprendizagem dos estudantes, levando-se em consideração a adoção de métodos diversificados e a contextualização do ensino. 
RIBEIRO, L. C., DOS ANJOS, V. H. A. e DOS ANJOS, D.S.C

A água como tema gerador do conhecimento químico: construindo um ensino-aprendizado contextual e cidadão no ensino de Química

\section{Referências}

ALBERT, Professor. 0 ciclo da água. YouTube, 2020. Disponível em:

https://www.youtube.com/watch?v=1zhaBOStQ1g. Acesso em: 28 jan. 2021

ALVES, Handerson Rodrigo; RIBEIRO, Marcel Thiago Damasceno. Uma proposta de sequência didática para o ensino de soluções. REAMEC - Rede Amazônica de Educação em Ciências e Matemática, Cuiabá, v. 8, n. 1, p. 302-322, jan./abr. 2020. Disponível em:

http://periodicoscientificos.ufmt.br/ojs/index.php/reamec/article/view/9748/pdf_1. Acesso em: 4 dez. 2020.

BERTHOLDO NETO, Emílio. Ensino híbrido: processo de ensino mediado por ferramentas tecnológicas. Ponto e Vírgula, n. 22, p. 59-72, 2017. Disponível em:

https://revistas.pucsp.br/index.php/pontoevirgula/article/view/31521/0. Acesso em: 2 dez. 2020.

CHACON, Eluzir Pedrazzi et al. Ensino de química: água e suas implicações na qualidade de vida. Areté - Revista Amazônica de Ensino de Ciências, Manaus, v. 9, n. 19, p. 281-291, jul./dez. 2016. Disponível em: http://periodicos.uea.edu.br/index.php/arete/article/view/238/238. Acesso em: 6 dez. 2020.

COELHO, Lucas Ribeiro; RODRIGUES, Carlos Alailson Licar; SÁ-SILVA, Jackson Ronie. Contribuições do Pibid do IF Sertão-PE ao ensino-aprendizagem de química. REAMEC - Rede Amazônica de Educação em Ciências e Matemática, Cuiabá, v. 8, n. 3, p. 135-152, set./dez. 2020. Disponível em: https://periodicoscientificos.ufmt.br/ojs/index.php/reamec/article/view/10607/7524. Acesso em: 25 nov. 2020.

DESENROLADO, Jonatha. Você já tomou $\mathrm{H}_{2} \mathrm{O}$ ?. YouTube, 2018. Disponível em: https://www.youtube.com/watch?v=BZH8E9v7cnM. Acesso em: 6 jan. 2021.

FOLEIS, Barbara Lina de Medeiros et al. O tratamento de água no contexto do ensino de química. Sinergia, São Paulo, v. 17, n. 1, p. 70-73, jan./mar. 2016. Disponível em: https://ojs.ifsp.edu.br/index.php/sinergia/article/view/80. Acesso em: 6 dez. 2020.

FREIRE, Paulo. Pedagogia do oprimido. 10. ed. Rio de Janeiro: Paz e Terra, 1981.

GABRIEL, Ernesto Dumba; RODRÍGUEZ, Juan Jesús Mondéjar; FLUENTE, Magali Torres. Processo de ensino-aprendizagem da Química nas Escolas Médias do Moxico sustentado no experimento químico escolar. Química Nova na Escola, São Paulo, v. 38, n. 3, p. 251-260, ago. 2016. Disponível em: http://qnesc.sbq.org.br/online/qnesc38_3/10-EQF-03-14.pdf. Acesso em: 21 mar. 2021.

GOUVE, Hércules Alan Carlotto et al. A relevância do tema água no ensino de ciências. Revista Monografias Ambientais, Santa Maria, v. 14, p. 157-171, 2015. Disponível em: https://periodicos.ufsm.br/remoa/article/view/20451/pdf. Acesso em: 27 mar. 2021.

MESSEDER NETO, Hélio da Silva; MORADILLO, Edilson Fortuna de. O jogo no ensino de química e a mobilização da atenção e da emoção na apropriação do conteúdo científico: aportes da psicologia histórico-cultural. Ciência \& Educação, Bauru, v. 23, n. 2, p. 523-540, abr./jun. 2017. Disponível em: https: / / www.scielo.br/scielo.php?pid=\$1516-73132017000200523\&script=sci_arttext\&tlng=pt. Acesso em: 20 mar. 2021.

MUNDO, Manual do. Como é feito o tratamento de água. YouTube, 2017. Disponível em: https://www.youtube.com/watch?v=cWBSFOVyiMl. Acesso em: $15 \mathrm{dez} .2020$.

PICHETH, Sara Fernandes; CASSANDRE, Marcio Pascoal; THIOLLENT, Michel Jean Marie. Analisando a pesquisa-ação à luz dos princípios intervencionistas: um olhar comparativo. Educação, Porto Alegre, 
RIBEIRO, L. C., DOS ANJOS, V. H. A. e DOS ANJOS, D.S.C

A água como tema gerador do conhecimento químico: construindo um ensino-aprendizado contextual e cidadão no ensino de Química

v. 36, n. esp., p. s3-s13, dez. 2016. Disponível em:

https://www.redalyc.org/pdf/848/84850103002.pdf. Acesso em: 8 jan. 2021.

PINHEIRO, Marlene Nogueira; BATISTA, Eraldo Carlos. 0 aluno no centro da aprendizagem: uma discussão a partir de Carl Rogers. Psicologia \& Saberes, v. 7, n. 18, p. 70-85, 2018. Disponível em: https://revistas.cesmac.edu.br/index.php/psicologia/article/view/770. Acesso em: 6 dez. 2020.

PRODANOV, Cleber Cristiano; FREITAS, Ernani Cesar de. Metodologia do trabalho científico: métodos e técnicas da pesquisa e do trabalho acadêmico. 2. ed. Novo Hamburgo: Feevale, 2013. Disponível em: https://www.feevale.br/Comum/midias/0163c988-1f5d-496f-b118-a6e009a7a2f9/Ebook\%20Metodologia\%20do\%20Trabalho\%20Cientifico.pdf. Acesso em: 30 nov. 2020.

RIBEIRO, Luiz Gustavo Gonçalves; ROLIM, Neide Duarte. Planeta água de quem e para quem: uma análise da água doce como direito fundamental e sua valoração mercadológica. Revista Direito Ambiental e Sociedade, v. 7, n. 1, p. 7-33, 2017. Disponível em:

http://ucs.br/etc/revistas/index.php/direitoambiental/article/view/4149. Acesso em: 8 jan. 2021.

SANT'ANA, Camila de Fatima; CASTRO, Denise Leal de. Cenário das produções acadêmicas acerca do uso de metodologias ativas no ensino de química: uma revisão dos últimos 8 anos. Scientia Naturalis, v. 1, n. 5, p. 194-205, 2019. Disponível em: https://periodicos.ufac.br/index.php/SciNat/article/view/3177. Acesso em: 27 mar. 2021.

SANTOS, Julio Gomes dos; RODRIGUES, Cae. Educação ambiental no ensino de química: a "água" como tema gerador. Revista Eletrônica do Mestrado em Educação Ambiental, Rio Grande, v. 35, n. 2, p. 62-86, maio/ago. 2018. Disponível em: https://periodicos.furg.br/remea/article/view/7643/5375. Acesso em: 5 dez. 2020.

SILVA, Brenno Ramy Teodósio da; MOURA, Francisco Marcôncio Targino de. Sala de aula invertida no ensino de química: limites e possibilidades nas vozes discentes. Revista Eletrônica Científica Ensino Interdisciplinar, Mossoró, v. 6, n. 17, p. 366-387, ago. 2020. Disponível em: http://natal.uern.br/periodicos/index.php/RECEl/article/view/2103/2101. Acesso em: $21 \mathrm{mar}$. 2021.

SILVA, Edilane Almeida da; SOUSA, Inaiara de; ANJOS, Débora Santos Carvalho dos. Metodologias inovadoras para o ensino de química orgânica e a sua relação com o meio ambiente. Revista Semiárido De Visu, Petrolina, v. 8, n. 3, p. 550-567, 2020. Disponível em: https://periodicos.ifsertao-pe.edu.br/ojs2/index.php/semiaridodevisu/article/view/1109/695. Acesso em: 30 mar. 2021.

SILVA, Nínive Matias Rodrigues; SILVA, Wanderson Diogo Andrade da; PAULA, Neidimar Lopes Matias de. $O$ ensino de química frente à experimentação: conhecendo diferentes realidades. Revista Debates em Ensino de Química, v. 2, n. 2, p. 70-78, out. 2016. Disponível em: http://www.journals.ufrpe.br/index.php/REDEQUIM/article/view/1316/1075. Acesso em: 17 maio 2020.

SILVA, Valdecir Manoel da; DANTAS FILHO, Francisco Ferreira; SILVA, Gilberlândio Nunes da. A inserção da música como recurso didático-pedagógico para o ensino de química. Conexões - Ciência e Tecnologia, v. 14, n. 4, p. 107-116, ago. 2020. Disponível em: http://conexoes.ifce.edu.br/index.php/conexoes/article/view/1541/1508\#. Acesso em: 19 mar. 2021.

SIMPLíCIO, Sidney Silva; SOUSA, Inaiara de; ANJOS, Débora Santos Carvalho dos. Estudo do impacto das metodologias ativas no ensino de química pelo Programa de Residência Pedagógica. Revista Semiárido De Visu, Petrolina, v. 8, n. 2, p. 431-449, 2020. Disponível em: https://periodicos.ifsertao-pe.edu.br/ojs2/index.php/semiaridodevisu/article/view/1090. Acesso em: 24 nov. 2020. 
RIBEIRO, L. C., DOS ANJOS, V. H. A. e DOS ANJOS, D.S.C.

A água como tema gerador do conhecimento químico: construindo um ensino-aprendizado contextual e cidadão no ensino de Química

ZANELLA, Liane Carly Hermes. Metodologia de pesquisa. 2. ed. Florianópolis: Departamento de Ciências da Administração/UFSC, 2013.

ZAPATEIRO, Gean Aparecido et al. Material didático como estratégia de ensino e de aprendizagem das ligações químicas. ACTIO: Docência em Ciências, Curitiba, v. 2, n. 2, p. 211-233, jul./set. 2017. Disponível em: https://periodicos.utfpr.edu.br/actio/article/download/6862/4538. Acesso em: 10 dez. 2020. 